Research Article

\title{
Study on Surrounding Rock Deformation Mechanism and Control of Roadway with Large Section and Extra-Thick Top Coal
}

\author{
Yuliang Yang $\mathbb{D}^{1,2}$ Xiaobin $\mathrm{Li} \mathbb{D}^{1},{ }^{1}$ and Pengfei $\mathrm{Li}^{1}$ \\ ${ }^{1}$ School of Energy and Mining Engineering, China University of Mining and Technology (Beijing), Beijing 100083, China \\ ${ }^{2}$ School of Coal Engineering, Shanxi Datong University, Datong 037003, Shanxi, China \\ Correspondence should be addressed to Yuliang Yang; 250219035@qq.com and Xiaobin Li; 1xb162197@126.com
}

Received 10 November 2020; Revised 18 December 2020; Accepted 4 March 2021; Published 19 March 2021

Academic Editor: Roger Serra

Copyright ( 2021 Yuliang Yang et al. This is an open access article distributed under the Creative Commons Attribution License, which permits unrestricted use, distribution, and reproduction in any medium, provided the original work is properly cited.

In order to solve the problem of safe and rapid excavation and support of roadway with large section and extra-thick top coal under complex geological conditions, the deformation mechanism and control of roadway are analyzed by means of field investigation, numerical simulation, theoretical analysis, and field practice, taking the 2203 transportation roadway of a mine in Shanxi Province as the engineering background. The results show the following: (1) the concentration of normal tensile stress in the middle of large-span roadway roof and end shear stress is significant, which may easily lead to the separation of roof and the extrusion deformation of surrounding rock; (2) the surface shear failure depth of the roadway side is large, and the insufficient length of the bolt, the small density of the protective side, and the insufficient support strength are easy to cause the bulge and splitting of the coal wall; (3) roof joints and fractures are developed, and the dirt band of different thickness occurs, so it is easy for the roof separation and the anchor solids to cut down along the weak surface of the dirt band; (4) the geological structure produces horizontal movement of surrounding rock, which easily leads to poor supporting effect of roadway roof and material deformation and failure. Finally, a safe and economic comprehensive support system of "high-strength, high-resistance, and high-prestressed anchor cable support system + high-strength support of the two sides roadway + U-shaped anchor cable combined truss" is proposed, and the control mechanism is explained and applied successfully in the field.

\section{Introduction}

In recent years, with the continuous improvement of key technology of large mining height fully mechanized top coal caving mining in extra-thick coal seam and the rapid development of mine mechanical and electrical equipment $[1,2]$, the kind of mining technology characterized by large mining face, extra-thick coal seam, and rapid advance speed has been gradually developed and popularized, and large section roadway has been applied. However, due to the complex geological structure, developed joints and fissures, the occurrence of multilayer dirt band and the high mining intensity, abnormal ground pressure behavior, and other factors, roadway deformation and damage is severe (roof fall and separation), which seriously restricts the safety and efficient production of the mine. Therefore, in order to solve the technical problems, there is an urgent need to find a safe, efficient, and rapid way about how to excavate and support in the large section and extra-thick coal seam under complex geological conditions.

Scholars at home and abroad have done a lot of researches on deformation and failure mechanism and control in the large section and thick coal seam roadway. By analyzing the stress change of surrounding rock and environment, Gao et al. [3] determined the influencing factors and regional scope of stress concentration in dynamic pressure roadway and proposed strengthening support in key areas and accelerating the advancing speed of working face to reduce the influence of mining dynamic pressure on roadway. Chu et al. [4] studied the mechanism and control method of large deformation of roadway in extra-thick coal seam in Lu Xin mining area and put forward an integrated support system with strong support surface and high toughness, which takes improving the elongation and impact toughness of supporting materials and increasing the surface area and stiffness of supporting components as the 
core. Yang et al. [5] analyzed the surrounding rock migration law of large cross section coal roadway with composite roof in extra-thick coal seam and the stress condition of bolt cable of roadway roof and proposed the stepped support technology of bolt and anchor cable. Yu et al. [6] optimized the roadway support parameters of super-thick composite top coal and put forward the high-strength combined support method of long bolt and cable. Wei et al. [7-9] studied the roof asymmetric deformation and failure characteristics of gob side coal roadway in large section fully mechanized top coal caving face and put forward the support countermeasures with "asymmetric anchor beam truss" as the core. Xiao et al. [10] analyzed the failure mode of thick roof coal roadway under deep mining conditions and proposed combining the support system of high-strength and high-pretension bolt with cable-stayed anchor cable beam and applied it in the field. In terms of rapid excavation and support technology of roadway, domestic and foreign scholars mainly do some researches on improving excavation equipment and optimizing auxiliary machinery and compare the typical integration mode of excavation, bolting, and transportation [11-13]. The above research results have laid a certain foundation for surrounding rock deformation and control of large section coal roadway in extra-thick coal seam. Generally speaking, the research results mostly optimize the support by increasing the bolt and cable support density, improving the strength of the support material, increasing the length of the anchor, or adding the surrounding rock control system combined with the deformation and failure characteristics of the surrounding rock. However, there are few reports on the rapid excavation and support of fully mechanized top coal caving roadway with large mining height under complex geological conditions, which are characterized by "analyzing the failure mechanism of surrounding rock, optimizing the control structure of surrounding rock, and reducing the supporting materials for surrounding rock."

This paper takes 2203 transportation roadway of a coal mine in Shanxi Province as the engineering background, combined with the unique complex geological conditions, the existing tunneling equipment, and the original support scheme in the process of excavation, which show the phenomenon of severe deformation of surrounding rock, large consumption of supporting materials, complex excavation support, and so on, which lead to the imbalance of production. Through field investigation, numerical simulation, and theoretical analysis, the surrounding rock failure mechanism of large section roadway in extra-thick coal seam is analyzed. Scientific, safe, and economic control measures are proposed to realize the stability control of surrounding rock and safe and efficient support. The research results provide a reference for similar conditions of roadway excavation support.

\section{Overview of the Project}

2.1. General Situation of Engineering Geology. The N8203 working face of a coal mine in Shanxi is mainly mining coal 3-5 with the buried depth of $350 \mathrm{~m}$. There are 6 layers of carbonaceous mudstone and gangue with different thickness, and the maximum thickness is about $0.5 \mathrm{~m}$. The average thickness of the coal seam is about $16 \mathrm{~m}$, the average dip angle is $3^{\circ}$, the strike length of the working face is $1250 \mathrm{~m}$, and the inclined length is $210 \mathrm{~m}$. The width of coal pillar between adjacent working faces is $20 \mathrm{~m}$. The fracture joints of top coal are abnormally developed, and the Proctor coefficient is 1.1. As shown in Figure 1, the immediate roof of coal seam is mudstone $(1.8 \mathrm{~m})$, the basic roof is fine sandstone $(8.3 \mathrm{~m})$, the immediate floor is medium sandstone $(2.1 \mathrm{~m})$, and the basic floor is medium fine sandstone $(5.8 \mathrm{~m})$. 2203 transportation roadway in N8203 working face is a rectangular large section roadway, with a width of $5.6 \mathrm{~m}$ and a height of $3.7 \mathrm{~m}$. The specific support scheme is shown in Figure 2.

2.2. Deformation and Failure Characteristics of Roadway in Original Support Scheme. With the support scheme in Figure 1, some phenomena are prone to occur in some areas of the roadway, including the failure of $\mathrm{W}$-shaped steel strip falling off the roof, roof bolt cutting, and coal pillar side swelling and splitting. Through a large number of field observations and analyses, it is found that the deformation and failure of roadway are mainly characterized by horizontal extrusion dislocation deformation, roof separation, and coal side internal extrusion. This can be summarized as follows.

2.2.1. Horizontal Extrusion Deformation of Top Coal. The combined action of high shear stress and horizontal compressive stress leads to the deformation of surrounding rock extrusion dislocation, forming extrusion fracture zone. The violent horizontal movement of roof leads to the failure of supporting structure, which is manifested as the bending deformation of $\mathrm{W}$-shaped steel strip and the failure of roof (Figure 3(a)).

\subsubsection{Overall Slip and Dislocation of Multilayer Gangue.} There are many layers of gangue with different thicknesses in the top coal structure. It is quite common for the gangue to fall off from the upper layer in the process of excavation. Then it is easy to cause the overall sliding and dislocation of the roof, resulting in the cutting roof bolt or roof falling accident (Figure 3(b)).

2.2.3. Side Heave Splitting Failure of Coal Pillar. The two sides of the tunnel have the characteristics of splitting and flaky failure for many times, and the large area of the overall mesh bag bulges at the side of the coal pillar, resulting in the serious deformation of the metal mesh and the shear of the bolt at the side (Figure 3(c)).

2.3. Roadway Deformation Observation. In order to clarify the supporting effect of the original support scheme, after the formation of the roadway section, the contact convergence measurement system is used to monitor the roadway 


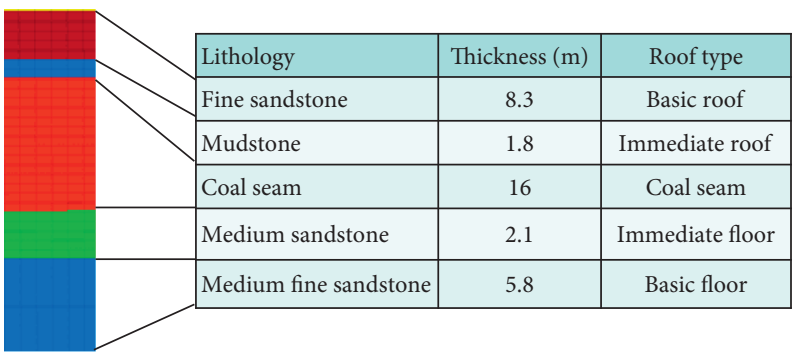

FIGURE 1: Generalized stratigraphy column of the working face.

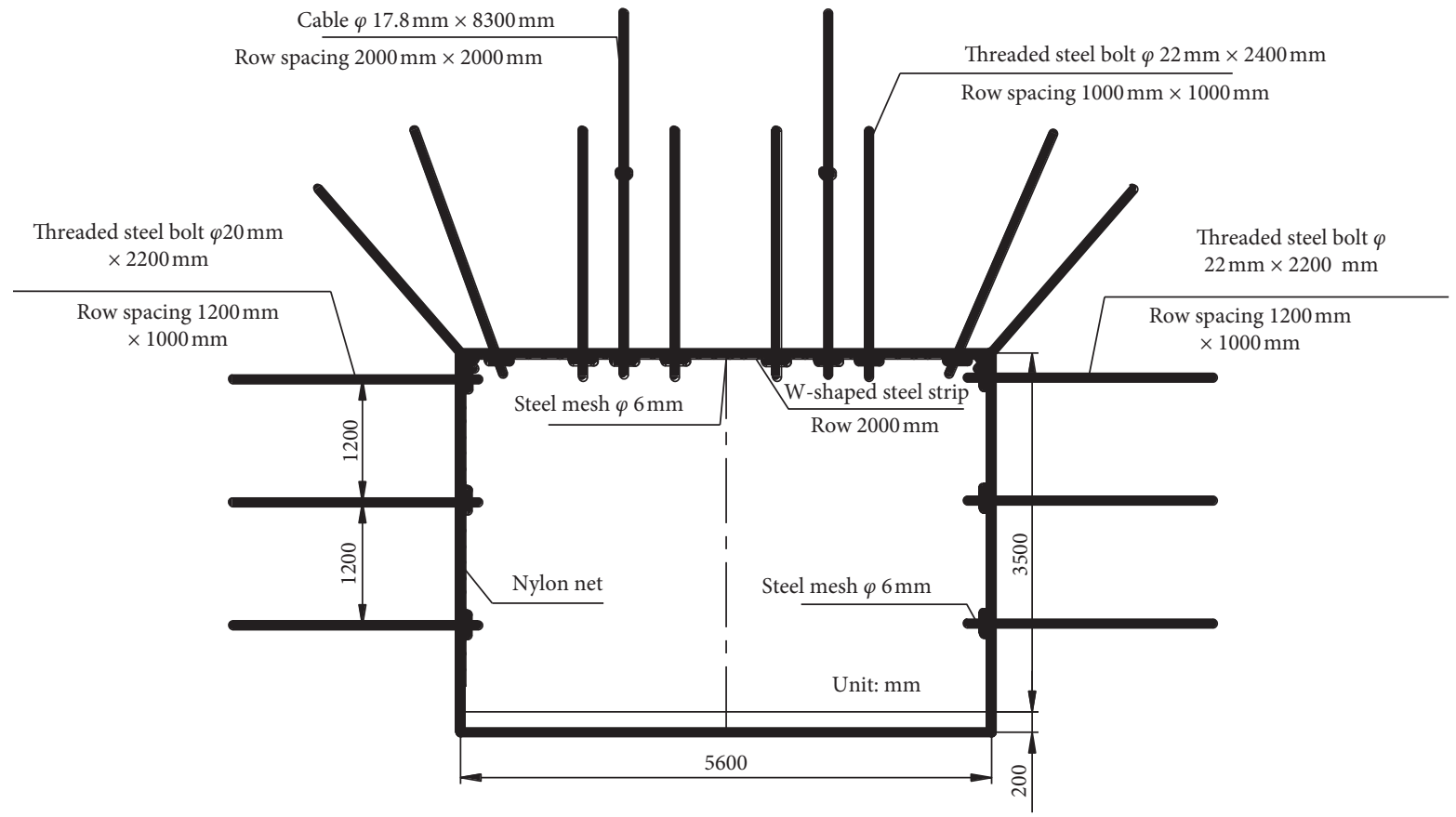

FIGURE 2: The support scheme of 2203 transportation roadway.

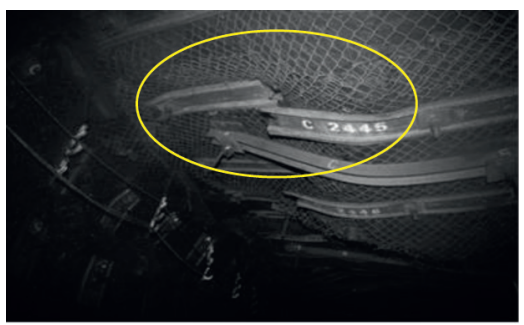

(a)

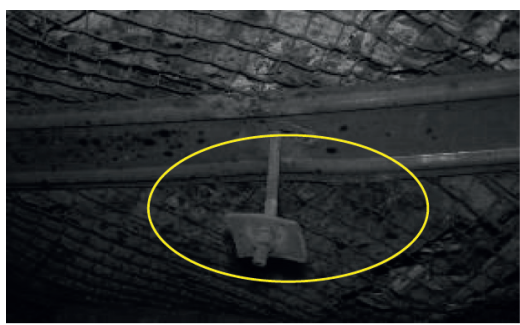

(b)

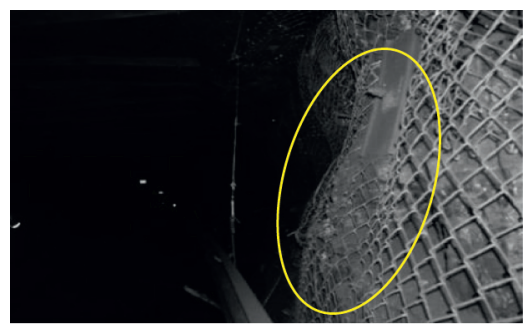

(c)

FIGURE 3: Actual picture of support failure of air return roadway of 2203. (a) Failure of W-shaped steel. (b) Roof bolt cutting. (c) Coal pillar bulge.

surface displacement, the roof separation meter is used to monitor the roof separation amount, and the bolt and cable axial force is monitored by the bolt hydraulic pillow.

A survey line is arranged at $600 \mathrm{~m}$ away from the opening of the roadway to analyze the convergence of surrounding rock (Figure 4). In the initial stage, the convergence rate of the roof is faster than that of the two sides, and the convergence rate of the roof and floor tends to be stable after a higher step convergence, and the maximum convergence amount is $295 \mathrm{~mm}$; meanwhile the convergence rate of the two sides increases linearly in the initial and middle stages and tends to be stable and lags behind the roof and floor, and the maximum convergence amount is $375 \mathrm{~mm}$.

Four different measuring points $1,2,3$, and 4 are arranged at $150 \mathrm{~m}, 450 \mathrm{~m}, 750 \mathrm{~m}$, and $1050 \mathrm{~m}$ away from 


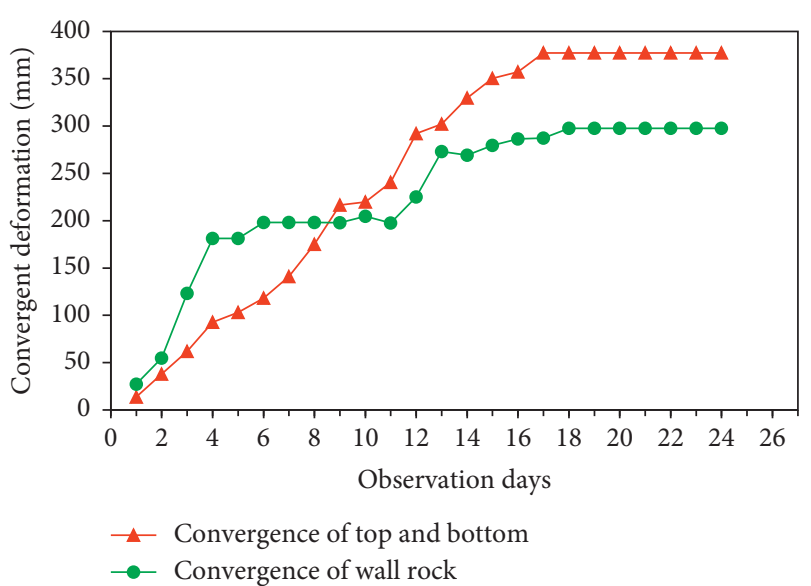

FIGURE 4: Convergence diagram of surrounding rock of roadway.

the roadway to monitor the roof separation. The statistical data are shown in Figure 5. After the excavation of roadway, the layer separation increases rapidly and tends to be stable after 10 days of monitoring, and the separation range is $18 \mathrm{~mm}-48.1 \mathrm{~mm}$. The bolt anchoring force of the roof and the two sides is monitored by the bolt hydraulic pillow. As shown in Figure 6, the growth rate of the anchoring force of the roof bolt is faster than that of the two sides. The maximum anchoring force of the top anchor is $65 \mathrm{kN}$, and the maximum anchoring force of the side anchor is $85 \mathrm{kN}$.

According to the analysis of the above monitoring data, the deformation of the surrounding rock of the two sides of the roadway is large and the deformation rate is fast. At the same time, according to the field observation, the local area has the phenomena of swelling and splitting, so the optimized scheme should strengthen the support of the two sides. Under the premise of ensuring the overall stability of roadway, the layout of roof anchor cable should be adjusted to increase the support stability and reduce roof separation.

\section{Numerical Analysis of Surrounding Rock Stability of Roadway}

According to the actual geological condition of 2203 transportation roadway, FLAC ${ }^{3 \mathrm{D}}$ numerical calculation model is established to analyze the influence of different top coal thickness and roadway width on surrounding rock stability and the stress state of support body in the original support scheme. The displacement boundary is adopted on the left and right, front and back, and bottom surface of the model, the stress boundary is used on the upper part, and the loading stress is the weight of overlying strata. The model size is length $\times$ width $\times$ height $=50 \mathrm{~m} \times 30 \mathrm{~m} \times 25 \mathrm{~m}$. The constitutive relationship is based on the Mohr-Coulomb model. The material parameters of each rock stratum in the numerical simulation are measured by the mechanics experiment of 2203 transportation roadway top and floor, as shown in Table 1.

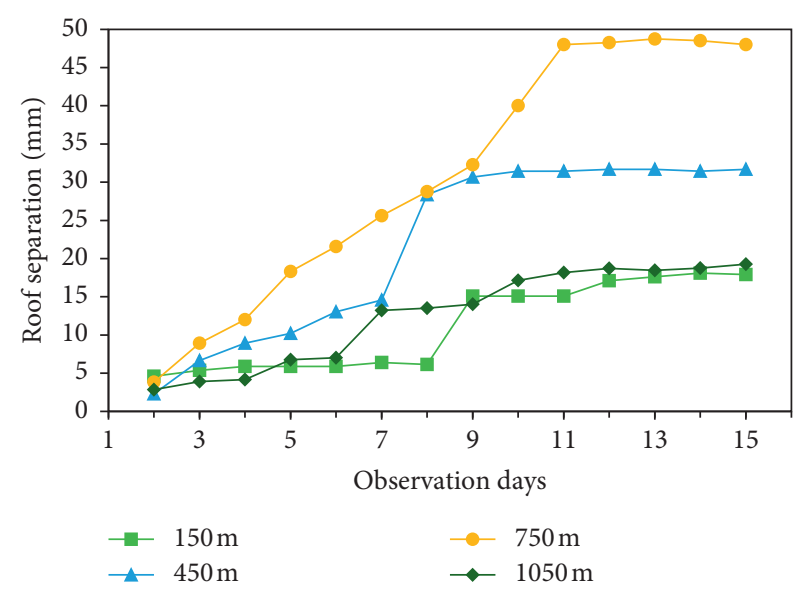

FIgURE 5: Roof separation of roadway.

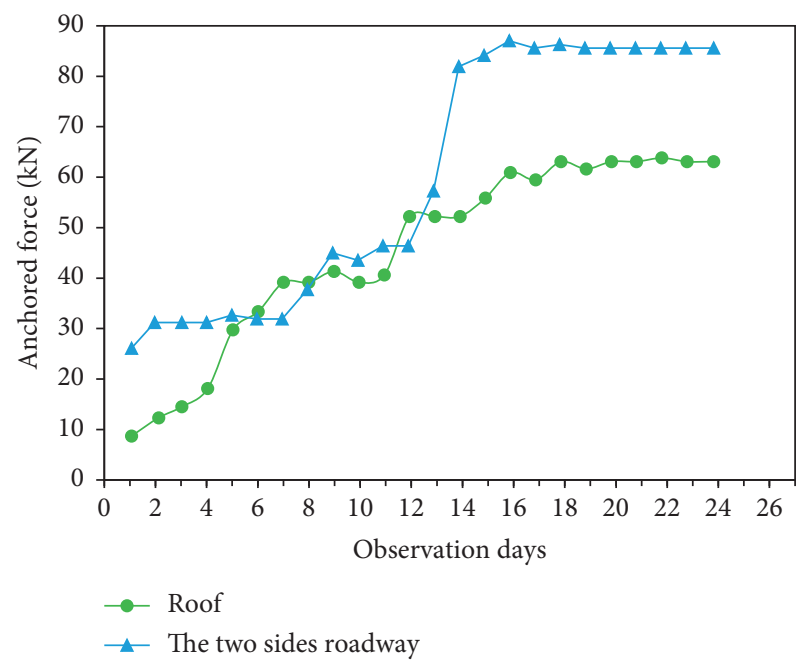

Figure 6: Anchoring force of bolt.

\subsection{The Influence of Top Coal Thickness and Roadway Width on Surrounding Rock Stability}

3.1.1. Influence of Top Coal Thickness on Deformation and Failure of Roadway Surrounding Rock. The simulation schemes with different top coal thickness of $4 \mathrm{~m}, 6 \mathrm{~m}, 8 \mathrm{~m}$, $10 \mathrm{~m}, 12 \mathrm{~m}$, and $14 \mathrm{~m}$ are designed to study the influence on deformation and failure of surrounding rock without support.

As shown in Figure 7, the convergence of roof and two sides increases linearly and monotonously with the increase of top coal thickness. At the same time, the convergence rate of roof is faster than that of two sides, and the thickness of top coal has a strong influence on roof subsidence.

Through numerical simulation, it is found that different top coal thicknesses have a greater impact on the plastic failure of the roof, but they have almost no impact on the two sides of the roadway and the floor. There is a small range of tensile stress in the middle of the roadway ledge, and it can be approximated that only the shear failure with a failure depth of $3.5 \mathrm{~m}$ occurs on the surface of the roadway ledge. As the thickness of the top coal increases, the plastic failure range of 
TABLE 1: Material parameters of each stratum in the model.

\begin{tabular}{lcccccc}
\hline Surrounding rock & $E(\mathrm{GPa})$ & $v$ & $C(\mathrm{MPa})$ & $\Psi\left(^{\circ}\right)$ & $\mathrm{P}\left(\mathrm{Kg} \cdot \mathrm{m}^{-3}\right)$ & $\Delta(\mathrm{MPa})$ \\
\hline Sandy mudstone & 12.5 & 0.38 & 16.34 & 23.6 & 350 & 2.52 \\
Packsand & 38.1 & 0.37 & 20.25 & 35.4 & 2550 & 1550 \\
Coal seam & 5.46 & 0.35 & 5.87 & 15.3 & 2650 \\
Medium sandstone & 42.8 & 0.35 & 22.24 & 32.2 & 4.28 \\
Middle-fine sandstone & 38.1 & 0.41 & 26.56 & 36.3 & 2750 & 5.18 \\
\hline
\end{tabular}

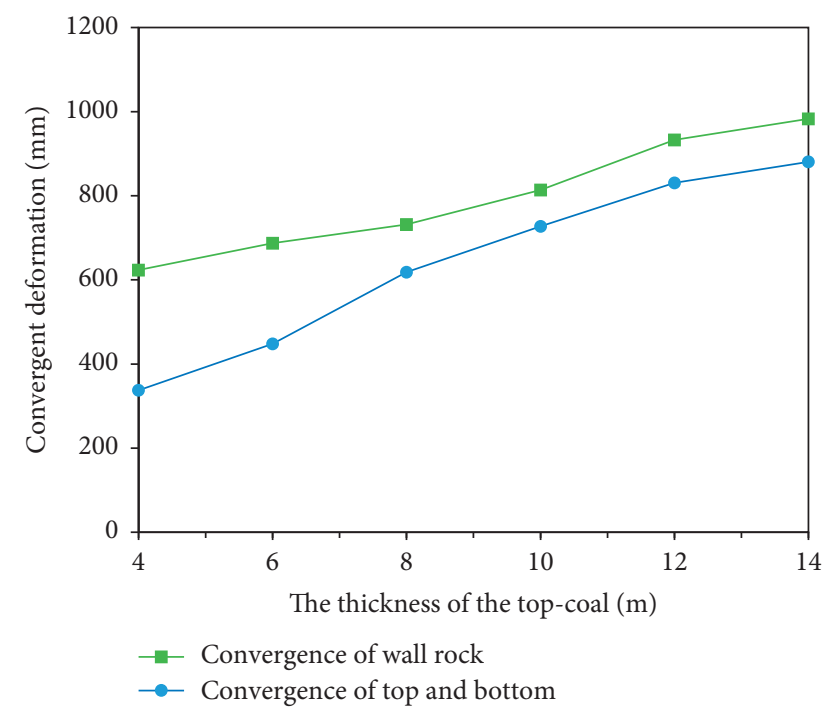

FIGURE 7: Convergence of surrounding rock with different top coal thickness.

the roof changes from an "inverted trapezoid" shape to an "arch shape." The reason is that when the thickness of the top coal is small, the coal-rock interface is prone to be separated from the layer, failing to form a falling arch. The middle position of the shallow part of the large-span roof is prone to tensile failure, and as the thickness of the top coal increases, the shear failure gradually develops to the deep part.

3.1.2. The Influence of Roadway Width on the Stability of Surrounding Rock. The model assumes that the roadway is $3.5 \mathrm{~m}$ high and the top coal thickness is $12 \mathrm{~m}$. Four different roadway widths of $4.5 \mathrm{~m}, 5.5 \mathrm{~m}, 6.5 \mathrm{~m}$, and $7.5 \mathrm{~m}$ are designed to analyze the vertical stress distribution in the middle of the roof under unsupported conditions.

By analyzing the changes in vertical stress at different positions of the roof under different roadway spans, the stress value gradually increases from $0 \mathrm{MPa}$ to the original rock stress. The vertical stress of the roof shows a downward trend as the width of the roadway increases. With the increase of the roadway span, the degree and scope of the damage to the surrounding rock in the shallow part of the roof become larger.

3.2. Force Analysis of Surrounding Rock Support Body in Original Support Scheme. In order to further understand the unreasonable layout of the original support plan, numerical simulation of the original roadway support plan was carried out. The stress of the anchor cable in the surrounding rock of the roadway was analyzed to lay the foundation for the optimized design plan.

3.2.1. Analysis of the Force of the Bolt. After the roadway is excavated, the initial surface displacement change rate of the roadway is relatively large. After the bolt support is reinforced, the axial force increases linearly, and the support strength increases accordingly. The degree of convergence of the roadway surface and the growth rate of the bolt axial force show a downward trend. The convergence of the roadway surface is similar to the parabolic growth. The axial force of the roadway bolt is distributed (Figure 8). The axial force of the roof bolt of the roadway is smaller than that of the two sides of the roadway, and the axial force of the bolt at the shoulder and socket is smaller. The axial force of the anchor rod in the middle of the two gangs decreases monotonously to the two ends, and the peak value is located in the middle of the right side of the roadway, and its value is $150 \mathrm{kN}$. The peak axial force of the roof bolt is located at the position of the anchor orifice, and it decreases monotonously toward the depth. According to the monitoring data analysis of bolt axial force, the maximum value is $78.5 \mathrm{kN}$, and the minimum value is only $33.5 \mathrm{kN}$. The peak value of the bolt axial force at the roadway ledge is located at the shallow and middle part of the bolt. Based on the above analysis, the optimization scheme should appropriately reduce the roof bolt support density, especially the support density at the top corner. Meanwhile, the support strength on both sides of the roadway should be strengthened, and the bolt with larger diameter and length should be selected.

3.2.2. Analysis of Anchor Cable Stress. As shown in Figure 9, according to the distribution of the axial force of the anchor cable on the roof of the roadway, the peak value of the axial force is located at the anchor cable in the middle of the roof, and the maximum value is $213.1 \mathrm{kN}$. The axial force of a single anchor cable is distributed in a "bell shape," with the peak value at the central monitoring points 4 and 5 , while the deep and shallow monitoring points have the smallest axial force. Therefore, comprehensively considering the distribution of roof bolts and anchor cable axial forces, the arrangement of roadway roof anchor cables should be reasonably selected to strengthen the support strength of the anchor cables in the middle of the roadway roof and reduce the amount of roof subsidence.

Through field investigation and numerical simulation, the failure mechanism of surrounding rock of the 2203 transportation roadway is analyzed: (1) The concentration of 


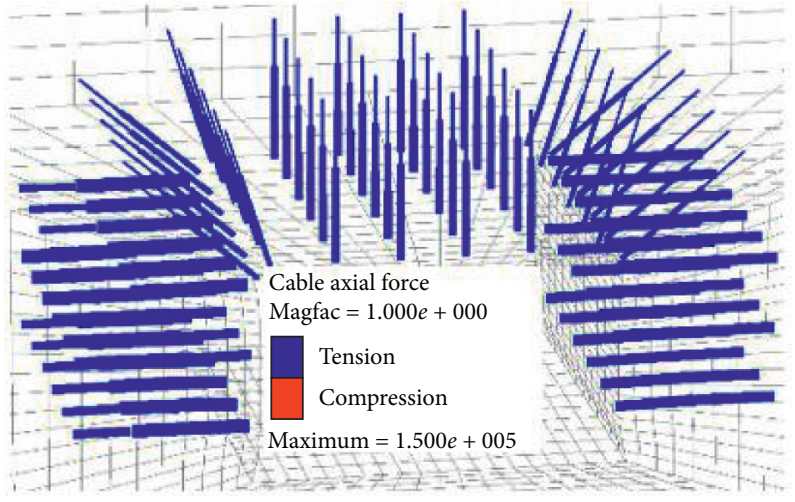

FIGURE 8: Distribution diagram of axial force of roadway bolt.

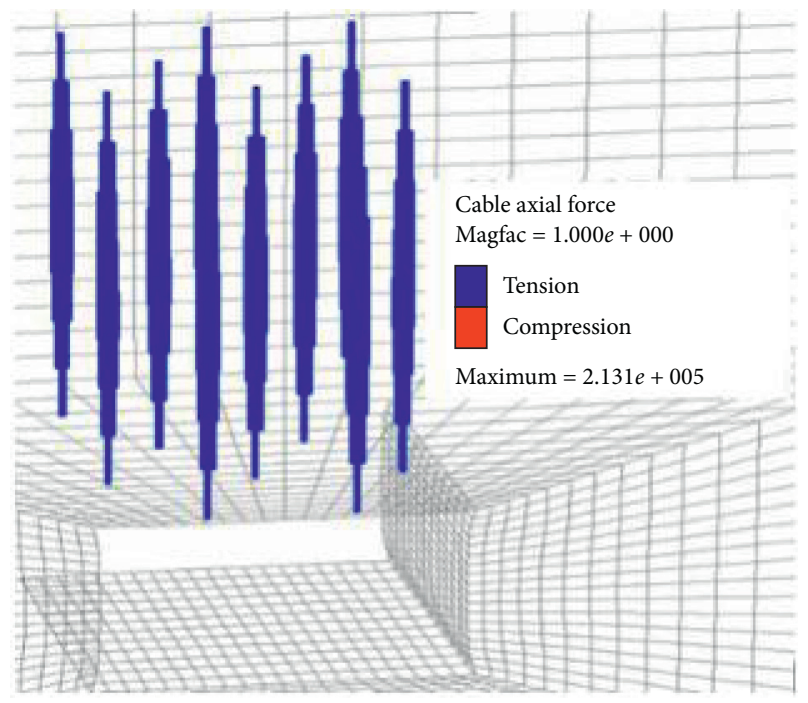

Figure 9: Distribution of axial force of anchor cable.

tensile stress and end shear stress appears in the middle of the roof of a large-span roadway. It is easy to cause roof separation and surrounding rock squeezing and dislocation deformation. (2) The surface of the two sides of the roadway has a large shear failure depth, the length of the anchor bolts at the sides is less than the failure depth, and the supporting density is small and the strength is low, which is easy to cause coal wall bulge splitting. (3) Roof joints and cracks are developed, and gangues of different thicknesses are present, which are prone to roof separation, and anchor solids are cut off along the weak surface of the gangue. (4) The geological structure induces the horizontal movement of surrounding rock, resulting in poor support effect and material deformation failure.

\section{Control Strategy and Technology}

4.1. Analysis of Control Countermeasures. According to the analysis of the failure mechanism of surrounding rock, it is necessary to optimize and adjust roof anchor cable, roof angle anchor bolt, and two sides' anchor bolt rationally in order to realize the stability control of roadway with large section of extra-thick top coal and at the same time to add reasonable support structure for roof separation, roof caving, and horizontal movement. On this basis, a safe and economic comprehensive support system of "high-strength, high-resistance, and high-prestress anchor cable support system + high-strength support of the two sides roadway + U-shaped anchor cable combined truss" is proposed.

(1) High-strength, high-resistance, and high-prestress yield anchor cable support system: At present, the overall deformation of roadway is large, the roof is detached, and the bolt cable fails. On the premise of meeting the high support resistance, the strength of bolt and anchor cable should be increased. At the same time, the support system allows certain deformation, which has the yield function to resist the influence of mining pressure near and on the working face. $20 \mathrm{MnSi}$ left-handed nonlongitudinal ribbed high-strength (HRB500) and high-resistance bolt of $22 \mathrm{~mm} \times 2400 \mathrm{~mm}$ was selected as the bolt body, and the yield pressure tube and arch highstrength tray were matched with the yield pressure distance of $35 \mathrm{~mm}$. Bird's nest anchor cable with diameter of $17.8 \mathrm{~mm}$ is selected to cooperate with double bubble yield pressure tube with pressure point of $21 \mathrm{t} \sim 25 \mathrm{t}$ and high-strength spherical tray. The metal mesh is made of cold drawn steel bars with a diameter of $6.0 \mathrm{~mm}$.

(2) High-strength support at the side: The upper bolt support system is adopted at side bolt. At the same time, two rows of bolts at the upper shoulder socket of the original plan are arranged at side of roadway. The spacing between rows is changed from $1200 \mathrm{~mm} \times 1000 \mathrm{~mm}$ to $1000 \mathrm{~mm} \times 1000 \mathrm{~mm}$, which enhances the bolt length and increases the support density, and, at the same time, high pretension is applied for timely support. The bolt body is the same as the roof support.

(3) U-shaped anchor cable combined truss: Original roof anchor cable "five-sided arrangement" layout changed into "two-two" layout with a row spacing of $1500 \mathrm{~mm}$. One row is between two $\mathrm{W}$ section steel belts and the other row is at both ends of the $\mathrm{W}$ 
section steel belts to replace the roof angle anchor rods (at an angle of $30^{\circ}$ with the vertical direction) for alternate support. W-shaped steel strip, 4 shallow bolts, and 2 deep anchor cables coupling support form U-shaped anchor cable combined truss. The combination of high-strength, high-resistance, and high-prestress shallow bolt and $\mathrm{W}$-shaped steel strip forms a stable bearing structure with good integrity, effectively controls the phenomenon of top coal crushing deformation and surface stress concentration, and achieves the effect of strong protective surface, which can be defined as the supporting system of first-level bolt composite beam. The roof angle anchor cable on the $\mathrm{W}$-shaped steel strip anchors the support system at the deep stable place, and the huge preload anchor cable effectively controls the phenomenon of shear stress concentration in the middle and end of the roof and limits the horizontal slip and dislocation between the weak surface layers of the gangue. Acting at a certain angle on the deep stability of the two sides, it hinders the top coal extrusion dislocation deformation to a certain extent. It can prevent pulling failure in the middle of top coal and protect loose coal and rock mass. Considering the overall support scope, the first-level composite beam support system can be defined as a "pallet" with certain thickness and strength, and the high-strength and high-prestress anchor cable at the end forms a strong locking structure under the bearing action of $\mathrm{W}$-shaped steel belt, which can be defined as the second-level anchor cable support structure. The two-level support structure acts synergistically to form the U-shaped anchor cable combined truss system (Figure 10).

In the original support scheme, the single anchor cable exerts a vertical upward force on the upper rock through point contact, and the surrounding rock cannot be in the three-direction stress state and the radial support range is limited, so it is difficult to effectively improve the stress state of surrounding rock. The anchor points of the U-shaped anchor cable combined truss are stable and in planar contact with the roof of the roadway, forming a closed bearing structure with the deformation of the anchor solid and making the neutral axis of the anchor solid move down; the anchor solid is in three-direction stress state in a wider range, and the horizontal deformation movement of the surrounding rock is effectively controlled.

\subsection{Stability Analysis of Coal Strata under the Support of} U-Shaped Anchor Cable Combined Truss. The roof rock layer of the roadway is a coal seam with an average thickness of $12 \mathrm{~m}$. The combined beam structure formed by the bolting support of a part of the coal seam at the lower part of the roof can be approximately regarded as thin plate with elastic body. The support strength provided by a single anchor cable is much larger than that of a single anchor bolt. Since the roadway span is far less than the axial length, it can be

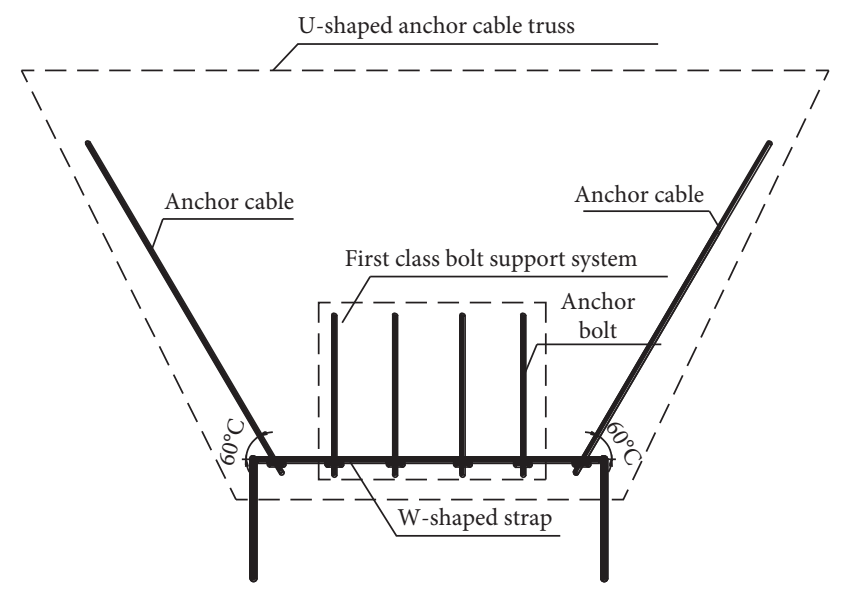

FIgURE 10: U-shaped anchor cable combined truss.

approximately considered as a plane strain mechanical model. According to the mechanical analysis, the combined beam structure of bolt support can be simplified into the model of "simply supported beam." One end is supported by coal pillar, the other end is supported by solid coal, and the end is suspended by two anchor cables anchored into the deep stable place, which is equivalent to adding two constraints. Figure 11 shows the model of "secondary statically indeterminate beam" [14].

As shown in Figure 11(b), symmetric semistructure can be calculated and analyzed as the load bornes by both $\mathrm{B}$ and $\mathrm{C}$ are equal:

$$
\begin{gathered}
\delta_{11}=\delta_{22}=\frac{l_{1}+l_{2}}{3 \mathrm{EI}}, \\
\delta_{12}=\delta_{21}=\frac{l_{2}}{6 \mathrm{EI}}, \\
\Delta_{1 p}=\Delta_{2 p}=-\frac{q\left(l_{1}^{3}+l_{2}^{3}\right)}{24 \mathrm{EI}} .
\end{gathered}
$$

The legislative equation of quadratic statically indeterminate is

$$
[\delta]\{X\}+\left\{\Delta_{p}\right\}=\{\Delta\} .
$$

Substituting equations (1)-(3) into equation (4), the following equation can be obtained:

$$
X_{1}=X_{2}=\frac{l_{1}^{3}+l_{2}^{3}}{4\left(2 l_{1}+3 l_{2}\right)} q,
$$

where $\delta_{i i}, \delta_{i j}$, and $\Delta_{i p}$, respectively, represent the displacement generated by unit force $X_{i}=1, X_{j}=1$, and load acting along the action direction at the action point of additional unknown force $X_{i}, m ; X_{i}$ is the extra unknown force, $N$; EI represents the bending stiffness of the beam, $N \cdot \mathrm{m}^{2} ; q$ represents the uniform load on the beam; $l_{1}$ and $l_{2}$ represent the support spacing: $l_{1}=0.8 \mathrm{~m}$ and $l_{2}=4 \mathrm{~m}$.

According to the solution of force method in structural mechanics, the support reaction of $\mathrm{B}$ and $\mathrm{C}$ can be obtained as follows: 


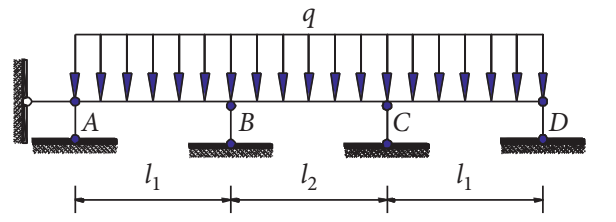

(a)

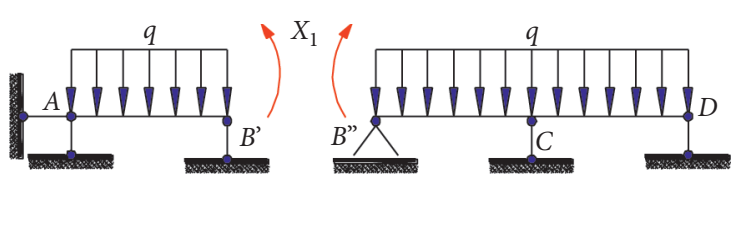

(b)

Figure 11: Simplification and calculation of roadway surface layer. (a) Simplified model of roof surface layer. (b) Calculation model of secondary statically indeterminate beam.

$$
Y_{B}=Y_{C}=\frac{5 l_{1}^{3}+6 l_{1}^{2} l_{2}+l_{2}^{3}}{4\left(2 l_{1}^{2}+3 l_{1} l_{2}\right)} q .
$$

Suppose the included angle between single anchor cable and vertical direction in the U-shaped anchor cable combined truss is $\alpha$, then the force along the direction of the single anchor cable of the truss is

$$
Y_{1}=\frac{Y_{B}}{\cos \alpha} \text {. }
$$

In order to avoid large-scale roof separation and instability and caving accidents, the minimum supporting force of a single anchor cable per meter along the axial direction of the roadway is as follows:

$$
Y_{\min }=Y_{1}=2.6 \gamma h \text {, }
$$

where $\gamma$ stands for the average unit weight of potential falling rocks, $\mathrm{kN} / \mathrm{m}^{3}$, taking $13 \mathrm{kN} / \mathrm{m}^{3}$; and $h$ is the potential falling height, $m$.

In the support scheme, the diameter of anchor cable is $17.8 \mathrm{~mm}$, and the maximum supporting force provided by anchor cable can reach $463 \mathrm{kN}$. After the optimization of the scheme, the row spacing of the U-shaped anchor cable combined truss is $2 \mathrm{~m}$, so the control range of a single anchor cable in the axial direction of the roadway is $2 \mathrm{~m}$, and the supporting force provided per meter is $231.5 \mathrm{kN}$. The potential falling height is calculated by numerical simulation, and the maximum value is about $6 \mathrm{~m}$. According to formula (8), the minimum supporting force required to be provided by a single anchor cable in each meter along the axial direction of the roadway is $202.8 \mathrm{kN}$, which is less than the supporting force provided by a single anchor cable in each meter along the axial direction of the roadway which is $231.5 \mathrm{kN}$. Therefore, the U-shaped anchor cable truss can control the stability of roof rock.

\section{Optimization of Support Scheme and Field Measurement}

5.1. Optimal Design of Support Scheme. According to the above analysis and considering the economic and construction costs, the optimized scheme (Figure 12) is implemented in the 2205 transportation roadway in the next working face.

5.2. Optimization of Support Technology. In order to realize the fast support of large section coal roadway, the support is divided into two times by using the technique of letting the pressure divide the support. For the first time, the roof $\mathrm{W}$-shaped steel belt anchor rod, anchor cable, and two upper bolts on each row of the two sides are installed. The second support adopts the $20 \mathrm{~m}$ position of lag heading face, and the anchor cable between the $\mathrm{W}$-shaped steel belt and two bolts on the lower part of the two sides is installed. The first support is timely supported along with the roadway, effectively controlling the roof separation. After the roof pressure is released, the anchor cable and bolt under the end are strengthened for a second time. It can not only effectively control the stability of the surrounding rock of the roof but also realize parallel operation and speed up roadway excavation.

The field test shows that the optimized supporting scheme and construction technology can effectively solve the problems of surrounding rock failure and slow supporting in roadway. After optimization, the plan is compared with the original plan. The two roof angle bolts of roadway section are transferred to two sides for installation. In this process, support time is saved about $210 \mathrm{~min}$ per $100 \mathrm{~m}$. Anchor cable is installed in the steel belt hole instead of bolt, 4 bolts and 2 anchor cables are saved in every 6 rows, and $262.8 \mathrm{~min}$ is saved in support per $100 \mathrm{~m}$. At the same time, multiprocedure parallel operation is more conducive to the realization of digging and supporting balance. The original 2203 transportation roadway has an average footage of $201 \mathrm{~m}$ per month, while the optimized scheme has an average footage of $321 \mathrm{~m}$ per month, an increase of nearly $60 \%$.

5.3. Field Measurement Analysis. To verify the support effect of the new scheme, a vertical hole is made for every $80 \mathrm{~m}$ along the direction of the opening between 2205 transport roadway and the roadway, and a total of 3 holes are arranged. Each hole is equipped with two sets of roof separation instruments. The deep base points are arranged at $7 \mathrm{~m}$ from the roof, and the shallow base points are arranged at $2.5 \mathrm{~m}$ from the roof.

As shown in Figure 13, the maximum amount of dissociation of the top plate of the $\# 1, \# 2$, and \#3 measurement stations is $1 \mathrm{~mm}, 2 \mathrm{~mm}$, and $3 \mathrm{~mm}$, respectively. By analyzing the swelling instability of surrounding rock, it can be considered that the roof has no separation phenomenon. According to the surface displacement observation, the relative displacement of roof, floor, and two sides is within a controllable range, which indicates that the supporting strength of bolt and cable is reasonable, and the deformation and failure of surrounding rock are effectively controlled. 


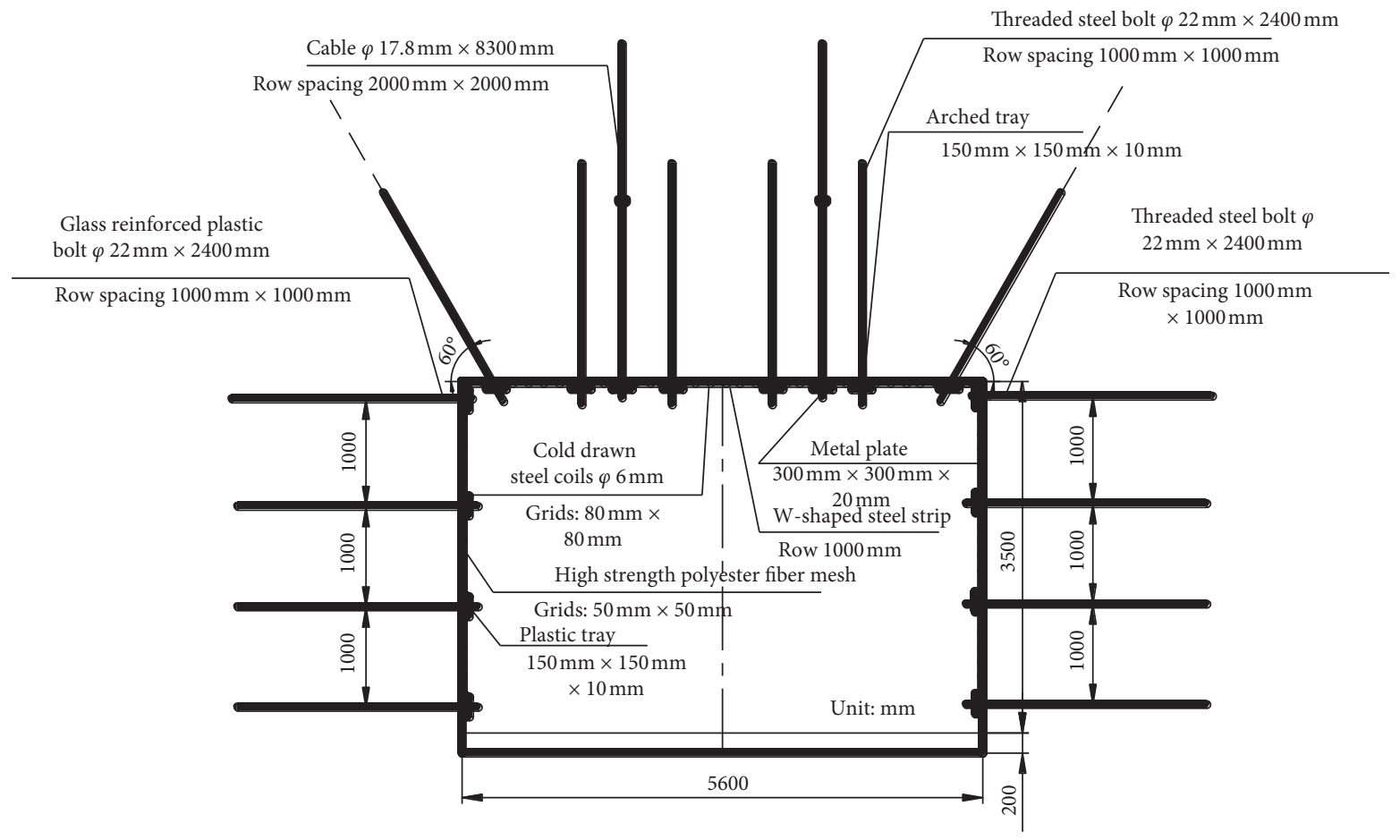

Figure 12: Supporting section diagram of 2205 transportation roadway.

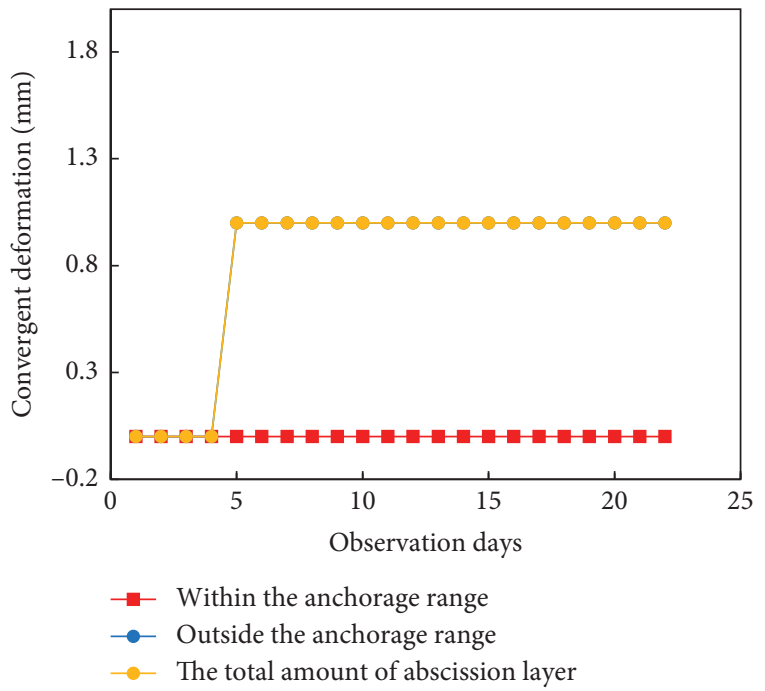

(a)

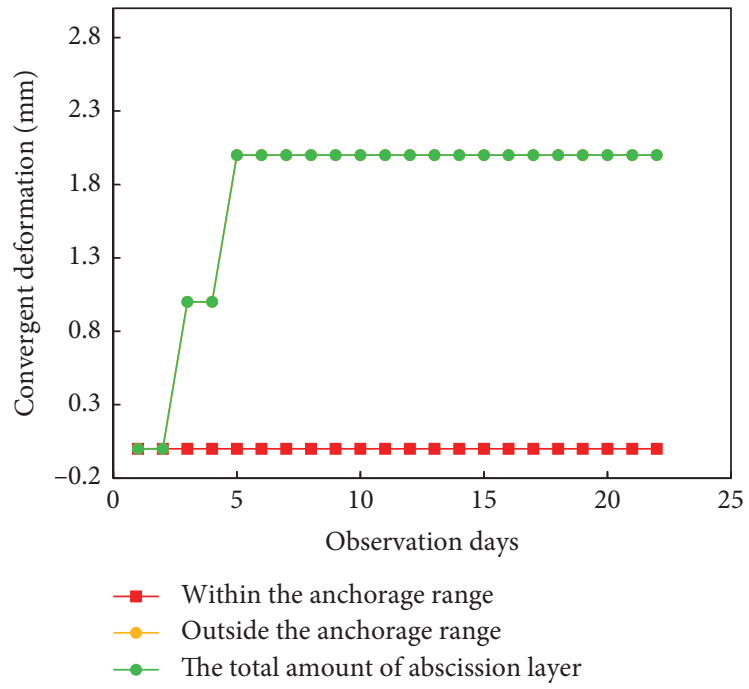

(b)

Figure 13: Continued. 


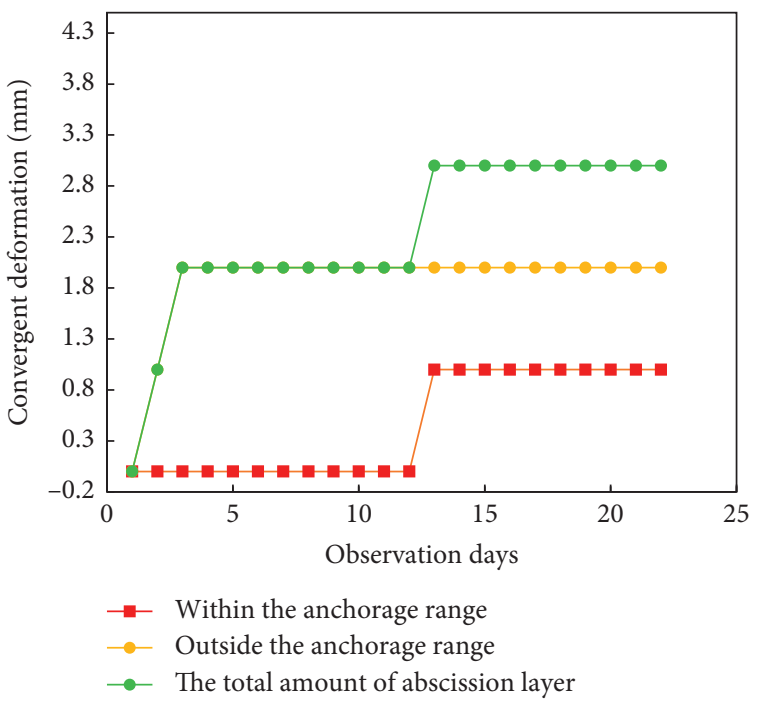

(c)

Figure 13: Roof separation of the station. (a) \#1 measurement station. (b) \#2 measurement station. (c) \#3 measurement station.

\section{Conclusion}

(1) Field investigation and numerical simulation results show that significant stress concentration, unreasonable support parameters, support structure, and complex geological conditions are the main reasons for the failure and deformation of surrounding rock.

(2) A safe and economic comprehensive support system of "high-strength, high-resistance, and high-prestress anchor cable support system + high-strength support of the two sides roadway + U-type anchor cable combined truss" is proposed. Reasonable support structure is added for roof separation, roof caving, and horizontal movement.

(3) The new support system effectively controls the failure and deformation of surrounding rocks and improves the excavation support efficiency. The field measurement results show that the average footage of the optimized scheme is $321 \mathrm{~m}$ per month, and the roadway rate is increased by $60 \%$.

\section{Data Availability}

The data used to support the findings of this research are included within the paper.

\section{Conflicts of Interest}

The authors declare that they have no conflicts of interest.

\section{Acknowledgments}

The authors gratefully acknowledge the financial support by the Key R\&D Program of Datong City, Shanxi Province (2019025) and the program of Shanxi Natural Foundation of China (201901D111305).

\section{References}

[1] J. H. Wang, "Key technology for fully-mechanized top coal caving with large mining height in extra-thick coal seam," Journal of China Coal Society, vol. 38, no. 12, pp. 2089-2098, 2013.

[2] H. M. Li, D. J. Jiang, and D. Y. Li, "Analysis of ground pressure and roof movement in fully-mechanized top coal caving with large mining height in ultra-thick seam," Journal of china Coal Society, vol. 39, no. 10, pp. 1956-1960, 2014.

[3] F. Q. Gao, J. S. Xue, and X. W. Yin, "Study on the law of dynamic pressure," Coal Science and Technology, vol. 43, no. 1, pp. 28-32, 2015.

[4] X. W. Chu, Y. Z. Wu, and M. Shi, "Large deformation mechanism and control technology of jointed brittle and extra thick coal seam roadway," Coal Science and Technology, vol. 46, no. 12, pp. 98-106, 2018.

[5] Q. S. Yang, S. Li, M. S. Gao et al., "Large section and thick layer composite roof coal roadway top supporting technology," Coal Mine Safety, vol. 46, no. 7, pp. 102-108, 2015.

[6] Y. J. Yu, Y. Zhao, Y. X. Hao et al., "Optimization of support parameters of large section coal roadway with huge thick composite roof coal," Journal of Liaoning University of Engineering and Technology, vol. 30, no. 5, pp. 693-696, 2011.

[7] Z. Wei, F. L. He, G. C. Zhang et al., "Failure mechanism and cable truss control of large-scale section gob-side entry roof with fully-mechanized caving," Journal of Mining \& Safety Engineering, vol. 34, no. 1, pp. 1-8, 2017.

[8] G. C. Zhang and F. L. He, "Asymmetric failure and control measures of large cross-section entry roof with strong mining disturbance and fully-mechanized caving mining," Chinese Journal of Rock Mechanics and Engineering, vol. 35, no. 4, pp. 806-818, 2016.

[9] G. C. Zhang and F. L. He, "Pillar width determination and surrounding rocks control of gob-side entry with large crosssection and fully-mechanized mining," Rock and Soil Mechanics, vol. 37, no. 6, pp. 1721-1736, 2016.

[10] T. Q. Xiao, J. B. Bai, X. Y. Wang et al., "Stability principle and control of surrounding rock in deep coal roadway with large 
section and thick top-coal," Rock and Soil Mechanics, vol. 32, no. 6, pp. 1874-1880, 2011.

[11] Z. G. Zhang, "Development trend and key technology of coal lane rapid driving system," Coal Science and Technology, vol. 44, no. 1, pp. 55-60, 2016.

[12] H. Zhao, "Current situation and Prospect of rapid tunneling technology of coal mine rock roadway in China," Coal Science and Technology, vol. 40, no. 1, pp. 5-7, 2012.

[13] Y. D. Liu, J. Lin, J. W. Yang et al., "Rapid excavation and support technology of super thick coal roadway based on the integration of excavation and anchoring," Coal Science and Technology, vol. 45, no. 10, pp. 60-65, 2017.

[14] Y. F. Zeng, Y. P. Wu, X. P. Lai et al., "Analysis of roof caving instability mechanism of large section roadway under complex conditions," Journal of Mining \& Safety Engineering, vol. 26, no. 4, pp. 423-427, 2009. 